Sergio Guilherme de Azevedo

Mestre em Desenvolvimento e Meio Ambiente, EMBRAPA-CPATSA.

E-mail:sergio@cpatsa.EMBRAPA.br

Cândido Roberto de Araújo

Engenheiro Agrônomo, EMBRAPA-CPATSA.

E-mail:candero@bol.com.br

Marc Piraux

Doutor em Agro-economia, Pesquisador do CIRAD e Professor

Visitante PPGCS/UFCG.

E-mail:marc.piraux@cirad.fr

\title{
O PAPEL E OS DESAFIOS DO FORUM NO ENFOQUE DO DESENVOLVIMENTO TERRITORIAL
}

\begin{abstract}
RESUMO
Neste artigo discutimos os objetivos, os resultados e o funcionamento do forum como espaço de nova governança nos territórios, o qual se constitui num dos eixos do projeto desenvolvido pela EMBRAPA, o CIRAD e a FAO em quatro municípios, no Piauí e em Pernambuco. São analisadas as razões da criação do forum e as implicações deste sobre os processos de desenvolvimento territorial. É enfatizada a importância da criação de competências pela formação, as estratégias de incentivo à participação, o fortalecimento das dinâmicas locais e a mobilização dos atores sociais.
\end{abstract}

Palavras-chave: forum, governança, políticas públicas

\section{ROLES AND CHALLENGES OF THE FORUM IN THE APPROACH OF TERRITORIAL DEVELOPMENT}

\begin{abstract}
In this article we discuss the objectives, outputs and the working out of the forum as a space of a new governance in the territories, which is one of the main lines of a project developed by the EMBRAPA, the CIRAD and the FAO in cities of Piauí and Pernambuco. We specifically analyze the reasons for creating the forum and its implications on territorial development processes. Are emphasized the importance of capacitating individuals thru their formation, the strategies used to incentivate the participation, the strengthening of local dynamics and the mobilization of social actors.
\end{abstract}

Key words: forum, territory, public policies 


\section{INTRODUÇÃO}

O governo brasileiro, com a criação da Secretaria de Desenvolvimento Territorial (SDT), no âmbito do MDA, optou pelo enfoque territorial como elemento norteador de políticas públicas, especialmente aquelas voltadas para o campo, especificamente para a agricultura familiar. Em várias regiões do Brasil, as políticas de desenvolvimento territorial, ao lado das políticas sociais de educação e saúde, têm sido apresentadas como uma forma privilegiada, para não dizer única, de intervenção do Estado.

$\mathrm{Na}$ implementação desta política houve grande dificuldade de encontrar vias e meios adequados para favorecer o desenvolvimento territorial, principalmente devido aos problemas referentes às competências e às metodologias necessárias. Um grande esforço tem sido organizado pelo Estado Brasileiro e pelas diferentes instituições parceiras para tentar responder a estas necessidades.

O nosso artigo tem com objetivo apresentar a experiência de um fórum social, especialmente o papel e o funcionamento, através de um projeto desenvolvido pela EMBRAPA, o CIRAD e a FAO (Tonneau, 2003) com quatro municípios nos estados de Piauí e Pernambuco. Este projeto visa o desenvolvimento de capacidades locais para convivência com o semi-árido e a melhoria das condições de segurança alimentar de famílias de agricultores pobres.

O projeto foi desenvolvido com instituições locais parceiras: Caatinga (ONG), Núcleo de Educadores Populares do Sertão de Pernambuco-NEPS (ONG) e Emater-PI. Beneficiou-se de financiamento do Ministério do Desenvolvimento Social e Combate à Fome - MDS, do Ministério do Desenvolvimento Agrário - MDA e da Embaixada da França no Brasil. Para apresentação desta experiência vamos discutir no primeiro momento os pressupostos do desenvolvimento territorial e as hipóteses do trabalho de animação para o desenvolvimento que foi realizado. No segundo momento, vamos apresentar a experiência concreta de implantação e funcionamento do fórum e, ao final, analisaremos os resultados do trabalho realizado.

\section{TERRITÓRIO E DESENVOLVIMENTO TERRITORIAL}

A principal justificativa para a utilização do conceito de desenvolvimento territorial no Brasil é que este surge como uma das possibilidades de resposta articulada entre o po- der público e a sociedade civil diante dos problemas apontados como causas do subdesenvolvimento, a saber: o tradicionalismo, a dominação e a exploração, a ausência de empresários e de dinamismo social.

O desenvolvimento territorial favorece a emergência de valores universalistas, baseados no resgate da identidade do território, busca reforçar a coesão social, os laços de solidariedade comunitária, objetivando ressaltar a eqüidade, o respeito à diversidade, a solidariedade, a justiça social, o sentimento de pertencimento e inclusão. Aumenta a capacidade de ação da sociedade civil e dos movimentos de base, com forte ação dos empresários portadores de iniciativa.

Trata-se de um processo específico de aproveitamento e produção de capital social, num processo de ação coletiva que se funda em laços de proximidade, reciprocidade e confiança mútua e que podem ser traduzidas "em crescimento e geração de riquezas” (Duncan, 2003). Putnam (1996) explica o desenvolvimento dos territórios pelo desempenho institucional das administrações ligado à falta de capital social, definido como "o conjunto de características da organização social, como confiança, normas e sistemas, que contribuam para aumentar a eficiência da sociedade, facilitando as ações coordenadas".

Não se pode falar de desenvolvimento territorial, sem fazer referências ao empowerment. Para Laverack e Labonte (2000), o empowerment pode ser definido como o meio pelo qual as pessoas adquirem maior controle sobre as decisões que afetam suas vidas; ou como mudanças em direção a uma maior igualdade nas relações sociais de poder, por exemplo, nas relações com quem detém recursos, legitimidade, autoridade e/ou influência. Para Vasconcelos (2004), o empowerment significa o aumento do poder e da autonomia pessoal e coletiva de indivíduos e grupos sociais nas relações interpessoais e institucionais, principalmente daqueles submetidos a relações de opressão, discriminação e dominação social. Nesta perspectiva, uma ação de empowerment estimula e favorece a coesão social e territorial das regiões e dos países onde ela é empregada como elemento harmonizador dos processos de ordenamento (regulação descendente), e de desenvolvimento (reação ascendente), das sociedades nacionais. (Duncan, 2003).

Estes dois processos de ordenamento e de desenvolvimento fazem referências às ações complementares (planejamento territorial e experimentação social) e às articulações entre dois atores principais (o Estado e a sociedade civil organizada). Um dos pontos cruciais na noção de 


\section{Sergio Guilherme de Azevedo, Cândido Roberto de Araújo \& Marc Piraux}

desenvolvimento territorial, e até o momento ausente nas experiências concretas já vivenciadas, é o entrecruzamento e a interligação entre as iniciativas locais e a ação dos poderes públicos em todas as esferas - nacional, estadual e municipal. Nesta perspectiva, o desenvolvimento territorial aparece como uma das possibilidades de resposta articulada, entre o poder público e a sociedade civil, para ultrapassar a distinção entre bottom-up - de baixo para cima - e programas verticais, top-down - de cima para baixo -, que são propostos a partir de uma perspectiva institucional.

\section{FÓRUM SOCIAL: UMA EXPERIÊNCIA DE GOVERNANÇA}

O projeto de Cooperação Técnica firmado em 2003 tinha como objetivo delinear uma metodologia de implementação do desenvolvimento territorial. A sua abrangência inicial era 10 municípios de 2 estados da região Nordeste (Piauí e Pernambuco). De maneira clássica, no seu inicio 2004, um diagnóstico inicial foi realizado para identificar os problemas, as experiências e as iniciativas portadoras de desenvolvimento. A falta de infra-estrutura (água, saúde, comunicação, transportes e eletrificação) e de serviços de assistência técnica não permitem a consolidação dos sistemas produtivos. Outro ponto relevante a considerar é a falta de experimentação social e técnica na região, sobretudo no Piauí. Enfim, o diagnóstico revelou que um dos limites para o desenvolvimento da região é a ausência de uma administração pública transparente e participativa, aliado a falta de informação e comunicação. A falta de articulação e diálogo entre os diferentes atores da sociedade, a falta de contratualização, tanto para definir os objetivos e elaborar os projetos como para executálos, é um ponto central. Por exemplo, ficou evidente que havia uma subutilização e/ou utilização inadequada dos recursos federal devido a falta de informação e desconhecimento dos atores territoriais.

Este último ponto justificava, no projeto, a necessidade de uma linha política (processo de intercâmbio político) que tratava de (1) formar e consolidar instituições locais e (2) articular as instituições locais e outras externas ao território, de maneira a consolidar um método comum de desenvolvimento, calcado na agricultura familiar e na convivência sustentável com o semi-árido. Também se espera que a articulação político-institucional identifique as competências de cada instituição envolvida e defina as responsabilidades de cada uma delas dentro do projeto.
A necessidade de criação de um espaço, o fórum social, capaz de convergir diferentes linhas de pensamento, ideologias e competências, sem perder o foco do desenvolvimento em discussões estéreis e de cunho político-partidário, pareceu-nos, de fato, o caminho mais indicado para a atingir os seguintes objetivos:

- Construir um lugar, um espaço de discussão, de diálogo, de intercâmbio entre os diferentes atores do desenvolvimento;

- Criar instrumentos e métodos de análise e de negociação próprios do território;

- Definir as grandes orientações de um projeto de desenvolvimento para ele;

- Traduzir estas orientações em ações concretas;

- Criar instrumentos de governança;

- Fornecer um espaço de representação aos atores da sociedade civil.

A construção do fórum num lugar que passamos a denominar "Território do Alto Sertão do Piauí e Pernambuco" aconteceu em 14 de setembro de 2004. A formalização do processo de criação ainda está em andamento. No decorrer das reuniões, duas grandes temáticas foram tratadas em paralelo.

A primeira delas tratava da "instituição-fórum", como espaço de diálogo entre os diferentes atores do território. No primeiro momento, a falta de comprometimento das entidades e das pessoas fez, no entanto, com que as discussões pouco evoluíssem. A observação de que pessoas engajadas socialmente e comprometidas com suas entidades poderiam ser a base de sustentabilidade social dele, levou-nos a repensar a abordagem metodológica. Chegouse a conclusão que havia necessidade de constituí-lo apoiando-se nos conselhos municipais de Desenvolvimento Rural (CMDRs). Este processo permitiria que o fórum pudesse coordenar as suas ações com os conselhos responsáveis pelas políticas rurais.

O fórum ficou constituído por representantes das prefeituras, dos Sindicatos dos Trabalhadores Rurais (STR), das associações, das instituições de apoio (ONGs), dos bancos e do Estado - Companhia de Desenvolvimento dos Vales do São Francisco e Parnaíba (CODEVASF), EMBRAPA, Programa de Combate à Pobreza Rural de Pernambuco - Renascer, Programa de Combate à Pobreza Rural do Piauí (PCPR), Secretaria de Produção Rural de Pernambuco (SPR), através do Instituto Pernambucano de Pesquisa Agropecuária (IPA). Deve-se observar que a atuação dos representantes dos conselhos do Fundo Municipal de Ação Comunitária (FUMAC) dos quatro municí- 
pios, dos representantes das associações de produtores e dos sindicatos foi determinante.

Com esta nova dinâmica o poder público, que já fazia parte dos conselhos do FUMAC, passou a observar com interesse o desenrolar das atividades do fórum, pois a participação da base das entidades tornou-se evidente e primordial nas discussões e encaminhamentos. No decorrer dos trabalhos surgiram duas propostas para a institucionalização. A primeira apoiava a idéia de que o fórum deveria se tornar uma entidade de direito, capaz de elaborar, implantar e gerir recursos e projetos, com todas as prerrogativas necessárias para tal. A segunda proposta buscava a manutenção de um espaço neutro, aglutinador de ideologias diversas, propositivo e capaz de discutir políticas públicas, elaborar planos e programas de desenvolvimento para o território. Com a prospecção de experiências que estavam ocorrendo em outros territórios ou regiões, a consolidação da situação institucional do fórum passou a ser rediscutida em novas bases.

As discussões passam, então, a serem focadas na busca dos "eixos norteadores". A necessidade de elaborar projetos orientados para a solução de problemas comuns e de impacto mensurável em diferentes níveis de intervenção, foi o objeto das reuniões. Estas reuniões tornaram-se itinerantes, cada município recebia o fórum, e mensais, seguindo um cronograma de atividades e visitas previamente definidos.

A realização de reuniões mensais permitiu a consolidação de grupos de trabalho para elaboração de propostas, tomando como referência as idéias discutidas anteriormente, fazendo um aprofundamento das mesmas em bases mais consistentes. Nestes grupos de trabalho duas questões emergiram: o problema da água e a falta de assistência técnica. Estes dois temas foram agrupados em uma única proposta, sob a forma de um projeto amplo, que posteriormente seria desmembrado em projetos de menor porte e mais direcionados. O tema da "água" foi abordado no âmbito da educação e da infra-estrutura, exigindo a elaboração e aplicação de um diagnóstico participativo bastante preciso, seguido de uma sistematização dos dados obtidos. Os atores perceberam as reais necessidades e possibilidades de ampliação do suporte hídrico, tanto para uso humano como para produção animal e vegetal. A severidade do período seco, no ano de 2005, pode ser amenizado com o uso dos resultados do diagnóstico no pedido de "situação de emergência". O envio rápido dos dados solicitados pela Defesa Civil, graças ao diagnóstico realizado, abreviou o tempo de tomada de decisão. Os sistemas produtivos e a falta de assistência técnica no território foram abordados de forma transversal na proposta de municipalização da agricultura, em moldes semelhantes ao que ocorre com a saúde, a educação e, como já se inicia, na assistência social e psicológica. Os desdobramentos que ocorreram após a apresentação do projeto tornam esta proposta, se não fundamental, mas complementar ao que o fórum discute e analisa na fase atual.

Uma reunião ampliada em julho de 2005 teve como pauta a apresentação, ao plenário, do projeto, seus possíveis desdobramentos e encaminhamentos necessários à busca de oportunidades de viabilização. Nesta reunião contou-se com a participação de todos os prefeitos do território, um deputado federal com base eleitoral na região, um assessor de outro deputado, superintendentes das superintendências regionais da CODEVASF com sede em Petrolina, em cuja jurisdição os municípios pernambucanos se encontram, gerentes das agências dos bancos que atuam no espaço, instituições federais, estaduais e privadas com ações e público de modo geral. O projeto foi solicitado pelo parlamentar presente e apresentado em sessão da Câmara dos Deputados em sessão ordinária em 05/ 08/2005, permitindo a realização das ações que caracterizarão a nova fase do processo.

\section{AS AÇÕES DO FÓRUM, RESULTADOS LIMITES E POSSIBILIDADES}

A sessão ordinária na Câmara dos Deputados foi um marco decisivo para legitimar a aceitação do projeto pela sociedade e definir os potenciais financiadores para implementar as ações no território. Além da análise e discussão de diversas experiências observadas em outras regiões ou territórios. Foi estabelecido um calendário de reuniões a cada 45 (quarenta e cinco) dias, aproximadamente, com reuniões intermediárias do Conselho Diretivo. Nestas seriam discutidos e analisados os encaminhamentos, ficando o fórum com maior capacidade de análise, pois os fatos e dados seriam apresentados e discutidos juntamente com as considerações do Conselho.

Os consórcios intermunicipais chamaram a atenção do fórum como uma ferramenta possível para alavancar o desenvolvimento, agregando assistência técnica, elaboração de projetos de desenvolvimento rural, permitindo parcerias e constituição de um grupo operativo flexível para as ações necessárias. 


\section{Sergio Guilherme de Azevedo, Cândido Roberto de Araújo \& Marc Piraux}

A experiência dos Consórcios Intermunicipais de Produção e Abastecimento de São Luis e região dos cocais no estado do Maranhão (CINPRA - São Luis e CINPRA Cocais) foi discutida numa reunião, em que representantes dos dois consórcios apresentaram suas experiências, dificuldades e avanços. Contou-se com a presença de três dos quatro prefeitos do Território e demais parceiros e membros. Como resultado desta ação, tivemos a plena aceitação do consórcio. Outra conquista decorrente das ações do fórum foi a implantação do "Programa de fomento de oportunidades comerciais da agricultura familiar", desenvolvido pela Fundação Lyndolpho Silva, em que beneficia agricultores familiares em um processo de transição agroecológica ou orgânica, apoiando e criando oportunidades de negócios para os agricultores do Território.

O fórum de Desenvolvimento Territorial do Alto Sertão do Piauí e Pernambuco apresenta resultados positivos, na medida em que revela a apropriação dos mecanismos do desenvolvimento pelos atores sociais e competências locais e leva a uma nova forma de governança. Este traduz uma dinâmica de desenvolvimento real. Ressalta-se ainda a mobilização e o interesse manifestados pelos diferentes parceiros. Percebeu-se muito claramente que localmente as pessoas, representando entidades, imprimem a dinâmica necessária. As reuniões tiveram públicos variáveis, com reuniões concorridas com mais de uma centena de pessoas e reuniões com pouco mais de vinte e cinco pessoas. Vinte reuniões foram realizadas, com a participação de um público fixo de aproximadamente $3 / 4$ do total presente a cada reunião. O poder público passou a designar seus representantes, permitindo a melhoria da base institucional em função da melhor interlocução observada.

O território ocupa uma área de $4.698 \mathrm{Km}^{2}$, nos $4 \mathrm{mu}$ nicípios já citados mas com as ações de articulação do "Programa de fomento das atividades comerciais da agricultura familiar”, os municípios de Jacobina do Piauí e Paulistana no Piauí e Petrolina em Pernambuco pouco a pouco passam a freqüentar as reuniões, e apresentar candidatos às capacitações. Este projeto acatou o fórum como seu "Conselho Territorial" contratou técnicos, articula com diferentes entidades a solução de problemas específicos dos setores produtivos, cria "bancos de conhecimento local" e de técnicos, apóia a EMBRAPA, o CIRAD e demais parceiros na discussão e solução das demandas territoriais. As discussões, extrapolando a capacidade de ação do fórum, exigiram a construção de uma nova institucionalidade que permitisse a gestão, implantação e elaboração de propostas de financiamento com respaldo jurídico - institucio- nal que ele não possuía. A união dos municípios em torno de objetivos comuns passa a ser base institucional das discussões sobre desenvolvimento, necessitando somente apropriar a forma jurídica em que ele será consolidado. Hoje, A criação de uma entidade executora dos projetos, um Consórcio Intermunicipal de Desenvolvimento, cria nova perspectiva para o desenvolvimento e criação de oportunidades. O poder público dos municípios de Acauã, Afrânio e Dormentes encaminhou para suas Câmaras Municipais o projeto-de-lei de criação do Consórcio Intermunicipal de Desenvolvimento Rural do Semi-Árido CINDER Semi-Árido (denominação provisória). Somente o município de Santa Filomena ainda não sensibilizou o poder público quanto às vantagens do consórcio. Sabemos que este processo é longo, que envolve receitas municipais e apropriação de ações que não são circunscritas aos limites municipais. Convênios com agentes financeiros (Banco do Brasil e Banco do Nordeste) estão sendo sinalizados, restando para sua efetivação a criação formal do Consórcio. O município de Petrolina em Pernambuco e os de Jacobina do Piauí e Paulistana no Piauí já iniciam os primeiros contatos.

\section{POR QUE O FÓRUM FUNCIONA HOJE?}

Gostaríamos de fazer uma análise das condições que julgamos ser importantes para que o fórum possa cumprir os seus objetivos. Iniciaremos fazendo uma reflexão sobre o espaço real e o território construído, a partir da experiência do fórum.

No início do processo, houve uma reflexão sobre a delimitação do território. A sua delimitação geográfica atingiria um número muito maior de municípios, principalmente do estado do Piauí. As limitações orçamentárias reduziram a atuação aos municípios de Acauã no Piauí e Afrânio, Dormentes e Santa Filomena em Pernambuco. As equipes dos parceiros do Piauí (EMATER, ONGs) foram convidadas a acompanhar os trabalhos na perspectiva de agregar os demais municípios ao fórum (Petrolina, Paulistana, Jacobina.). Julgamos que começar com um pequeno território permitiria a sua apropriação pelos atores locais, porque é um espaço que faz senso para eles. Um espaço grande demais encareceria e dificultaria o processo. Hoje, cada município arca com as despesas de seu pessoal e anfitrião com alimentação, espaço e demais necessidades locais. Este é uma prova da implicação do município e apropriação pelos atores locais. 
Desde o início do processo, julgamos ser de fundamental importância a disposição e a vontade dos atores para realizar essa experiência. A equipe que organizava e animava o fórum não se desencorajou das primeiras reuniões, que foram muito difíceis nas condições encontradas. Também e a ele ligado, a equipe utiliza o tempo para explicitar o processo, os objetivos e implementar a metodologia de sua implantação. Esta estratégia procurou assegurar o (re)conhecimento dos diversos atores, suas competências e a dinâmica social a ser implementada. É importante respeitar o ritmo das pessoas em cada localidade e respeitar a regularidade do processo (a agenda, com duas reuniões mensais pode, também, ter influenciado o esvaziamento pelas entidades). O empenho dos atores no processo é condição necessária para a continuidade e o êxito do trabalho, de fato, temos hoje praticamente dois anos que ele funciona com uma real participação.

\section{A CRENÇA NA PARTICIPAÇÃO E A LEGITIMIDADE DA REPRESENTAÇÃO}

O fórum é um lugar de representação e de participação efetivas apesar da fragilidade e do fracasso das organizações da sociedade civil.

- Este fato, grave do ponto de vista do desprendimento e comprometimento exigido para esta forma de abordagem do desenvolvimento, levou-nos a buscar na base das instituições pessoas com liderança nata e preocupação com a realidade. Nesta perspectiva houve um trabalho de discussão sobre a representatividade dos membros e como o Fórum é visto como um espaço de intercâmbio entre os diferentes atores do território, esta explicitação levou a definir critérios de participação. Os critérios foram de dois tipos: critérios de representação (quais são as diferentes categorias sociais que deviam ser representadas) e critérios pessoais de compromisso. Os critérios escolhidos são os seguintes: ter capacidade de um bom diálogo, ter boas idéias, ter compromisso, gozar de credibilidade e responsabilidade perante as comunidades, ter conhecimento da realidade do município, ter experiência com trabalho social, residir no município, ter disponibilidade de tempo, ser indicado por entidades representativas - Prefeituras, Sindicato dos Trabalhadores Rurais, ONGs, Representantes das Associações

- A demanda, a percepção e as ações concretas surgi- das desta demanda são importantes também para estimular a motivação e a participação, para começar o trabalho concretamente. Foi acordado que deveriam ser escolhidos temas suportes para um exercício de elaboração de projetos; primeiramente, só com os membros e depois apresentando e consolidando as idéias de projetos com parceiros tanto técnicos como financeiros. Este exercício resultou na expressão das necessidades da população, baseado nas experiências de desenvolvimento bem sucedidas e apropriado pelas populações. Com metodologia especial, conseguir que o planejamento rural não seja dominado pelos tomadores de decisão, distantes da realidade. Foi uma condição importante para a participação.

- O Fórum foi analisado como um lugar de democracia, onde todos têm o direito de falar, de expressar sua visão política do futuro, mas sem cair no ativismo político partidário.

- Teve também uma relação entre a participação e um processo de formação, sobre o qual retornaremos seguidamente.

- Enfim, o peso político do Fórum como espaço privilegiado de discussão e apropriação das ferramentas necessárias ao desenvolvimento surgiu a legitimidade e a dinâmica do processo que ele implementou, levando à participação dos prefeitos.

A análise dos critérios escolhidos mostra uma preocupação com o "capital social” (Abramovay, 1998). As pessoas, representando entidades, passaram a constituir o capital social desejado como ferramenta básica das discussões e apropriação da percepção de que eles são os atores principais do processo de desenvolvimento. Os parceiros iniciaram a construção do espaço de discussão e a abordagem de problemas e soluções apoiados nos poderes constituídos. Este fato, tomado per si, permitiria a evolução consistente do espaço para um fórum atuante e efetivo nos seus objetivos. Porém, as particularidades do território, com seu histórico de dominação político-fundiária - particularidades estas muito presentes no semi-árido nordestino - impediram a apropriação do espaço pelo público-alvo e o poder público pouco ou nada fez no início das discussões. A sociedade civil organizada foi esquecida. A leitura que fazíamos da realidade local nos levava a pensar que naquele espaço necessitaríamos de um corpo social engajado e responsável pelo próprio desenvolvimento. A transformação de simples e pobres agricultores no capital social ocorreu quando da apropriação do fórum 


\section{Sergio Guilherme de Azevedo, Cândido Roberto de Araújo \& Marc Piraux}

por eles, dinamizando as discussões, buscando oportunidades de interlocução e repensando sua realidade como ator principal do processo de desenvolvimento.

\section{A EXPERIÊNCIA DO FÓRUM: O APRENDIZADO DE NOVOS ARRANJOS INSTITUCIONAIS}

Uma metodologia de planejamento que permite criar um local de aprendizagem onde as pessoas vão buscar informações, analisar as experiências, experimentar e avaliar. A metodologia privilegiava a elaboração de projetos para promover experiências. O pressuposto é que não há soluções prontas, que se necessita de uma experimentação para encontrar pistas. A idéia é promover experimentações sociais, técnicas e institucionais que, acompanhadas, vão ser espaços de produção de referências. Compartilhar as informações disponíveis para os membros terem uma visão comum da situação ou pelos menos conhecer as opiniões e as visões dos parceiros. Serviu para dar aos técnicos um conhecimento mínimo da zona para engajar um diálogo com as populações. Os resultados permitiram ao fórum um conhecimento da realidade do território que não existia de modo oficial, permitindo novas avaliações por parte do poder público e sociedade civil. De fato, foi na discussão com as comunidades, nos diferentes encontros, que os grandes traços da situação da região foram definidos e apropriados. Identificar, acompanhar, registrar e analisar as experiências sociais na perspectiva de reverter este quadro, esta situação.

Para permitir o funcionamento do fórum e ativar a participação e a representação dos atores, uma organização foi pensada. Foram estabelecidas em contrato amplamente discutido, regras claras de envolvimento, responsabilidades e critérios de comportamento para facilitar a articulação entre a iniciativa privada, organização da população (comunidades, sindicatos, associações), instituições de apoio (governamentais e não-governamentais) e poderes públicos. Foram criados, baseados no estatuto proposto, Conselhos Diretivos Municipais, com representação do poder público, associações, sindicatos dos trabalhadores rurais e igrejas, além da figura do Coordenador Municipal e, de modo central, um Conselho Diretivo, composto pelos Coordenadores Municipais, Conselhos Diretivos Municipais e um Secretário Executivo. A plena ação destes conselhos somente ocorreria nos últimos meses. Estes arranjos institucionais que prevêem a institucionalização do fórum implicam em formas de consolidá-lo como locus da governança terri- torial. Isso permitiria que o próprio fórum pudesse articular as suas ações com os Conselhos responsáveis das políticas rurais. Enfrentar este desafio implica em encontrar boas soluções para antigos problemas dos programas de desenvolvimento: aproximar os tomadores de decisão das realidades sociais; garantir a participação das organizações da sociedade civil; dinamizar as administrações municipais carentes de recursos humanos e financeiros; e viabilizar o funcionamento dos conselhos municipais. Em resumo, garantir as práticas da boa governança. Também buscando uma "entidade" com personalidade jurídica capaz de executar, elaborar projetos e implantá-los, gerindo os recursos, contratando técnicos.

Podemos considerar que o fórum, no seu estatuto, ao criar os Conselhos Municipais e o Conselho Diretivo com as representações bem fundamentadas, estabeleceu uma relação com o poder público. Este assumiu seu lugar após perceber a apropriação dos mecanismos e propostas pela sociedade.

A busca de competências engajadas foi primordial no avanço do processo no fórum. Foi nesta perspectiva que se definiu priorizar a implantação da Universidade Camponesa. Para além do impacto na montagem de projetos produtivos, deve-se notar que após a consolidação da base social nas associações, sindicatos e conselhos do FUMAC e CMDR, o público pouco a pouco se tornou mais efetivo em termos de participação. A participação dos jovens agricultores que estavam neste processo de capacitação possibilitou a participação das comunidades as quais eles estavam vinculados. O fórum viabilizou-se pela participação efetiva dos atores e pela efetividade das discussões.

\section{FÓRUM, COMPETÊNCIA E DINÂMICAS LOCAIS}

Na perspectiva de potencializar competências, percebeu-se que a formação deveria ir além de uma simples capacitação técnica. Ela deveria permitir aos beneficiários entender a relação entre a inovação e o sistema de produção, identificar as necessidades de adaptação, favorecer estas adaptações, mobilizando os meios das políticas públicas. A capacitação técnica (domínio das tecnologias) está incluída numa reflexão global sobre o sentido e os impactos esperados desta tecnologia no sistema. Isso implica em um itinerário pedagógico que respeita as seguintes etapas: análise da realidade, definição de estratégias de transformação dos sistemas de produção, apresentação e discussão das técnicas, capacitação (domínio das técnicas). De 
fato, a formação é uma formação pela pesquisa/ação: observação, modelização/teorização, experimentação, avaliação... (método cientifico hipotético-dedutivo). Adota-se nesta formação a Pedagogia da Alternância, com a organização de sessões quinzenais (aulas presenciais) de dois dias de capacitação, com atividades de campo entre cada sessão, e acompanhamento das atividades do projeto. Esta pedagogia fortalecerá a ação dos mobilizadores sociais.

Estes jovens, denominados inicialmente "Agentes de Desenvolvimento Rural" - ADR e, hoje, "Agentes de Desenvolvimento Sustentável” - ADS, fazem parte de ação transversal nos projetos que apóiam o território e, cremos ser a ação de maior impacto de médio e longo prazo dos projetos. São agricultores da região, escolhidos pelas comunidades, interessados e com competências (alfabetizados, engajamento social, interesse para a "coisa técnica", responsabilidade, credibilidade e etc) para assumir um papel de agentes de desenvolvimento rural. A primeira turma formou vinte e cinco jovens. A segunda turma, com trinta e dois jovens, terminará o ciclo de capacitação em junho de 2006. Mais uma turma de trinta e dois jovens está programada para término em novembro de 2006.

A figura do ADS vem para cobrir uma imensa lacuna em ações que formem agricultores familiares e lideranças, assim como dos próprios técnicos de suas organizações e das organizações de apoio, ou seja, pessoas com maior capacidade de atuar como atores protagonistas neste processo de geração/difusão. A Universidade Camponesa com o objetivo de oferecer aos jovens camponeses uma oportunidade de desenvolvimento social através de sua participação nas ações típicas da universidade: ensino, pesquisa e extensão. O desafio é fornecer uma formação inicial para facilitadores, a fim de que eles possam entender a filosofia de um projeto de desenvolvimento sustentável e de manejo dos recursos naturais, baseada na interação entre as perspectivas, interesses e projetos dos agricultores familiares e de suas organizações e no referencial teórico, analítico e prático das disciplinas científicas. Isso contribuiria muito para a implementação de um projeto de desenvolvimento sustentável almejado.

A inserção destes jovens no processo de desenvolvimento ocorre em um primeiro momento com articuladores locais em suas comunidades. Passam a ser referência técnica local ao atuarem mais diretamente como capilares na assistência técnica e elaboração de projetos do "Programa Nacional de Fortalecimento da Agricultura Familiar" PRONAF. Hoje, oito jovens da primeira turma atuam no município de Acauã no Piauí junto a técnicos projetistas credenciados pelo Banco do Nordeste, avaliando, diagnosticando, discutindo e auxiliando na elaboração de projetos em suas comunidades. O projetista remunera os ADS por produto (projeto elaborado e liberado). O Banco do Nordeste, parceiro de grande importância do fórum, ao perceber a qualidade das abordagens dos projetos apresentados, demandou à EMBRAPA um projeto específico de capacitação para o território.

\section{DESAFIOS À CONTINUIDADE DA EXPERIÊNCIA}

Uma das dificuldades ligadas à continuidade do processo e ao acompanhamento, são os meios humanos e financeiros, e a questão da institucionalização do consórcio e da agência de cooperação técnica.

A animação exige tempo e deslocamentos, portanto financiamento. A procura da autonomia paradoxalmente necessita de uma intervenção externa que deve ser do governo federal para garantir a independência do processo. Como é de costume, os financiamentos do governo não são os mais adequados para garantir a continuidade, as necessidades de financiamento de ações de prospecção, de oportunidades etc., demandam recursos nem sempre disponíveis ou utilizáveis. A constituição de fundo de reserva consolidado em entidade de direito capaz de viabilizar as respostas às demandas pode suprir as necessidades.

O Consórcio Intermunicipal de Desenvolvimento $\mathrm{Ru}-$ ral do Semi-Árido (CINDER Semi-Árido), caso seja implantado, caso não ocorram dificuldades de ordem política que possam retardar a constituição de direito da entidade, será a figura executora que se buscava nas discussões de institucionalização do fórum, deixando-o como o espaço de discussão e aconselhamento, traçando diretrizes e programas para o desenvolvimento territorial. A figura do CINDER Semi-Árido potencializará as ações do programa, viabilizando equipes técnicas, projetos e capacidade de gestão e implantação de ações. Dentro do consórcio, e com a ajuda financeira da Fundação Lyndolpho Silva (criada pela articulação EMBRAPA-Contag), um setor será criado para a gestão da assistência técnica, baseada na rede de agentes animadores, os ADS. Eles facilitarão a articulação entre as comunidades e as instituições, animarão a reflexão, identificarão as necessidades e proporão projetos para as comunidades e aos produtores. Reconhecemos que a assistência técnica ainda é necessária, mas como facilitadora do processo, em particular, produzindo material pedagógico e 


\section{Sergio Guilherme de Azevedo, Cândido Roberto de Araújo \& Marc Piraux}

referências. O pressuposto é a capacidade de resposta dos ADS aos questionamentos da comunidade, que se apóiam na experimentação realizada na propriedade do agricultor. Essa agência de assistência técnica vai assumir a capacitação dos agentes e fornecer os meios mínimos (deslocamento, material didático, compensação financeira). A implantação das ações do "Programa de fomento de oportunidades comerciais da agricultura familiar", com o fórum deliberando na forma de Conselho Territorial também cria expectativas muito promissoras. Tanto como apoio aos sistemas produtivos como fortalecimento dele. Os dois processos estão sendo implantados e deverão ser avaliados. No futuro, ele consolidaria seu papel de articulador, dinamizando processos sem cair na rotina institucional. Este é um grande desafio, que significa inovar sobre os arranjos institucionais.

\section{CONCLUSÕES}

A necessidade de elaboração de um plano de desenvolvimento, como forma de iniciar os entendimentos com a SDT/MDA, oficializando o Território é demanda do fórum e mais um grande desafio, pois a premissa de liberdade de atuação e discussão não pode ser descartada. Um outro desafio está ligado ao fato de fortalecer as reflexões sobre as políticas públicas em função da realidade do lugar. Enfim, isto pode ser consolidado a partir de uma elaboração de referências pedagógicas e didáticas do desenvolvimento do processo, levando à construção de objetivos e metas consistentes para a proposição de políticas públicas botton-up.

A região sofre da falta de articulação e de comunicação entre os diferentes atores territoriais, de contratualização, tanto para definir os objetivos e elaborar os projetos como para executá-los, falta de experimentação social e técnica na região, a ausência de uma administração pública de qualidade e a raridade da informação e da comunicação reforçou a evidência da necessidade "de espaço":

- de aprendizagem;

- de informação e de articulação.

Estes espaços foram respectivamente os ADS e o fórum. $\mathrm{Na}$ experiência que foi apresentada, o espaço foi apropriado e as condições para o desenvolvimento foram iniciadas. Achamos que o ponto central do seu sucesso foi a criação de competência pela formação para ativar a participação, para fortalecer as dinâmicas locais e mobilizar os atores sociais. Os agentes de desenvolvimento sustentável são a ligação entre a base, as comunidades e o fórum. O território e o resultado de um processo específico de aproveitamento e produção de capital social. Assim, o seu sucesso depende da qualidade das inter-relações entre recursos, atividades econômicas, necessidades da população, distribuição de riqueza, ações dos grupos sociais, governança e apoio do Estado e das suas instituições num espaço que faz sentido pelos atores locais.

Gostaríamos de insistir sobre o caráter experimental de tal processo. Não tem receitas, tem uma metodogia, tem eixos aglutinadores mas, sobre tudo, tem uma vontade de uma equipe e um respeito do ritmo das comunidades locais. Este processo ilustra perfeitamente que o território é uma construção social, um "espaço de projeto", produto do entrelaçamento de projetos individuais e coletivos, em que se instituem processos de identificação e de negociação dos interesses comuns e conflitantes. Envolvendo atores e instituições locais que, não necessariamente, defendem os mesmos grupos, interesses e idéias, mas trabalham de forma articulada, buscando consensos em torno de um tipo de desenvolvimento. Os desafios mais importantes hoje são conseguir projetos produtivos, melhorar as condições de vida da população para concretizar as ações do fórum. Para atingir tais objetivos, sugerimos algumas perguntas:

- Quais serão as conseqüências da construção de uma entidade executora sobre o funcionamento do dele, sobre as ações dessenvolvidas no território e sobre o controle social? Como ele pode ficar no seu papel definido, um espaço de negociação?

- Quais serão as perspectivas de reconhecimento pela SDT?

A experiência de construção deste lugar foi sugerida como exitosa para ser replicada pela FAO na construção do Território do Sertão do São Francisco na Bahia. Apesar de também estar no semi-árido tem particularidades que diferem do Território do Alto Sertão do Piauí e Pernambuco, mas a metodologia de abordagem pode ser de grande valia.

\section{REFERÊNCIAS BIBLIOGRÁFICAS}

ABRAMOVAY R. O capital social dos territórios: repensando o desenvolvimento rural. Seminário Sobre Reforma Agrária e Desenvolvimento Sustentável. Fortaleza, 23-25 de Novembro de 1998. 
DUNCAN, M. O desenvolvimento territorial: o projeto do MDA in Jean Philippe Tonneau, Pedro Carlos Gama da Silva, Waltemilton Vieira Cartaxo, Eduardo Assis Menezes, Lydda Gaviria "Desenvolvimento Territorial e Convivência com o Semi-Árido Brasileiro" - Experiências de Aprendizagem. Relatório Final. EMBRAPA semi arido. Petrolina 2003. 46p.

LAVERACK, G.; Labonte R.,. A planning framework for community empowerment goals within health promotion. Health Policy Plan, v.15, n.3 p.255-262. 2000.

PUTMAN, R. D. "Comunidade e Democracia: a experiência da Itália Moderna”. Rio de Janeiro: FGV. Tradução Luiz Alberto Monadim, 1996.
TONNEAU, J. P.; GAMA, da S. P. C, VIEIRA, W. C., ASSIS M. E, Gaviria L. "Desenvolvimento Territorial e Convivência com o Semi-Árido Brasileiro" - Experiências de Aprendizagem. EMBRAPA, FAO, FAGRO, CIRAD, Relatório final e Anais do Seminário, Petrolina, EMBRAPA Semi-árido, 30 setembro de 2003, 42p.

VASCONCELOS, E. M. (org.). A saúde nas palavras e nos gestos: reflexões da Rede Educação Popular e Saúde. São Paulo: Hucitec, 2001. 